\title{
VERTICAL VERSUS HORIZONTAL COMPARISON IN CONTEMPORARY APPROACHING OF CONSUMER LAW
}

\author{
APPERÇUE SUR LA METHODOLOGIE VÉRTICALE VERSUS \\ HORISONTALE DE COMPARAISON EN DROIT DE LA \\ CONSOMMATION CONTEMPORAIN
}

\author{
ABORDAREA COMPARATISTĂ VERTICALĂ VERSUS \\ METODOLOGIA COMPARATISTĂ ORIZONTALĂ ÎN \\ MATERIA DREPTULUI CONSUMATORULUI
}

\begin{abstract}
The following article attempts to dismantle the assumptions that the vertical comparative methods, especially those using a bottom-up approach, from national to international level, are surrounded by intricacies related to the internalization of international norms, in the context in which the contemporary administrative and legislative measures tend to be divided into two categories: (a) those related to the State's economic intervention (public policy of direction) and (b) those pertaining to the protective and anticipatory legal intervention (public policy of protection). The fundamental issue that needs to be addressed is whether it is possible to refine the concept of longitudinal comparative approach, correlated to the intrinsic elements of traverse comparative approaches of contemporary Consumer Law.

Furthermore, there is a contrast to be marked between longitudinal comparison, based on analogies which are made between legal systems of the past, in order to extract essential features valuable in the approaching of contemporary legal order and, in an antagonistic manner, the traverse comparative approach of Consumer Law which valorises the main trends of contemporary legal orders, while simultaneously approaching features from several contemporary legal systems. Several studies have been focusing on the problematic of horizontal/vertical comparative methodology, as well as to the intricacies characterizing the longitudinal/traverse comparative approaches of Consumer Law; nevertheless, there is space left for investigating the extent to which vertical comparative methodology represent an adequate means to deliver accurate information on legal transplants and conceptual trends in national legal orders related to
\end{abstract}


the number of the compared legal systems, both from the angle of bilateral comparative law, while the comparison is carried out as a dichotomy of two legal systems, as well as from the perspective of multilateral comparative law, when the comparison takes place between more than two legal systems, using a variable-oriented approach. As an explanatory example of vertical comparative approaches of Consumer Law, we will use the comparative analyses at national level on the judicial meaning of the notion of mandatory rules and the various degrees in the extent to which a mandatory rule must be applied through the means of consumer legal protection. Secondly, vertical comparative approaches are also helpful in investigating the national 'absorption' of specific regulations on the professionals' pre-contractual liability, which takes shape in all the cases where the professional - consumer relationship implies the duty of transparency.

Keywords: vertical comparison; horizontal comparison; longitudinal comparative approach; traverse comparative approach; Consumer Law.

\section{Introductory comments}

Vertical comparative methodology and the use of vertical comparison in contemporary approaching of Consumer Law seems to be surrounded by a veil of defiance, mostly due to the enclosing under this camouflage of a range variety of hybrid methods of comparison, especially the longitudinal/traverse comparative approaches. While vertical, top-down methods of comparison are most likely to be practiced in the field of Consumer Law research, typically in the context of the internalisation of international norms and regulations by national legal orders, vertical, 'bottom-up' legal comparison, as referring to the transposition of legal concepts from national to international level, has conventionally been viewed with scepticism during the last decade, frequently due to the assumption of inherent incompatibility between the national and international legal orders. Whereby national legal orders are likely to be seen as receptacles for international legal requirements and therefore to incorporate international concepts into the national legal system, terminology and ideology, vertical, 'bottom-up' legal comparison, on the other hand, seems 'unnatural' as it refers to the transposition of legal concepts, or the ideologies behind those concepts, from national to international level ${ }^{1}$. 
The aim of the present contribution is to investigate to which extent vertical comparative methodology is an adequate means to deliver accurate information on legal transplants and conceptual trends in national legal orders related to the number of the compared legal systems, from the angle of bilateral comparative law, while the comparison is carried out between two legal systems, as well as from the perspective of multilateral comparative Consumer Law, when the comparison takes place between more than two legal systems. Such an approach can be seen as a variable-oriented research, the main advantage of which being the increasing number of the objectives compared.

This contribution takes a close look at vertical bottom-up and vertical top-down methods of comparison in the field of Consumer Law, using a strict regulatory dichotomy between horizontal and vertical methodologies of comparison (i), in an attempt to reach a substantial informational equilibrium between the advantages and the disadvantages of both techniques of comparison (ii). The last part of our contribution shines a light on the evolution of longitudinal vs traverse methods of comparative research applied to Consumer Law institutions and technical mechanisms (iii).

At the outset, we consider it useful to clarify which are the cornerstones of vertical versus horizontal comparison methodology valorising the main trends of contemporary legal orders, while simultaneously approaching features from several contemporary legal systems. After some explanatory assertions on vertical/horizontal comparison essentials, also providing highlights on the scientific literature focused on this type of comparative methodology (section 2), section 3 focuses on aspects suggesting the roles played by the hybrid/cross-echelon methods of comparison when applied to Consumer Law concepts and their interference with the vertical comparative methodology. The forth section deals with practical aspects that are persistent in upward, downward and horizontal comparison, in cases such as the comparative approaching of the emerging of professionals' precontractual liability (a) and an explanatory example of vertical comparative approaches of Consumer Law, that one can use for illustrating the comparative analyses at national level on the judicial meaning of the notion of mandatory rules and the various degrees in the extent to which a mandatory rule must be applied through the means of consumer legal protection (b). 


\section{Highlights on the scientific literature focused on the vertical vs horizontal comparison methodology}

Several studies have been dedicated to the problematic of horizontal/ vertical comparative methodology, as well as to the intricacies characterizing the longitudinal/traverse comparative approaches of Consumer Law. Professor PIETERS introduces a distinction between nearby goals, intermediate goals and distant goals ${ }^{2}$ of comparative approaches applied to law, while mentioning that this distinction is not radical and that in some respects an intermediate goal may be launched as a distant goal for comparative legal research; by nearby goals, the cited author means to indicate those functions law comparison seems to imply quasi automatically; if the researcher pursues with more remote functions, the latter are labelled as the intermediate and distant goals of the comparative method. As Hirschl argues, the horizontal comparative approaches may benefit from the transgression beyond the multiple-description methodology ${ }^{3}$ usually deployed in comparative legal analyses towards the next level of comparative inquiry applied to legal concepts, which imply causal inference with controlled longitudinal comparison. Professor EBERLE, on the other hand, notes that hybrid horizontal comparison and multicultural comparative approaches are essential for obtaining accurate results, thus underlying that 'decoding is an essential part of the work of comparative law: discovering and translating the invisible powers in a legal culture leads to uncovering the patterns of order that actually operate within a society'4. As MURKENS describes it, 'a culturally-sensitive inquiry needs to ask whether it is legitimate to "import" foreign legal ideas into the national legal arena if it means divorcing those ideas from the cultural context in which they originated's.

Other commentators suggest that the risk of conducting a onedimensional comparative analysis through the means of vertical approaching 'can be mitigated by considering multiple aspects of the particular legal concept under consideration, which should typically include both substantive (such as the social function of the legal concept) and procedural elements'6. As an argument in favour of vertical bottom-up comparative approaching of law, BIGNAMI mentions that it is necessary for comparative scholarship to move beyond the traditional national focus and to recognize the growing 
importance of international legal systems as objects of study in their own right and as catalysts for change at the domestic level'7. MONATERI emphasizes the importance of vertical comparative methodology, stressing that 'as regards comparative law, the drive to locate method beyond specificity - and the conviction that this ambition can be achieved - continue to govern the framing of research'; in particular, while referring to horizontal comparison of legal orders, 'there is no single method which can claim to operate pandisciplinarily, as it manifests itself in manifold ways both within and across disciplines' of Law8.

It is important to underline the existence of four stages of comparative research associated with the vertical methodology of comparison; these four stages have been elaborated and explained by MOMIROV and FOURIE9. The first step consists, as the cited authors explained, in the formulation of a hypothesis based on the observation of apparent similarities between two or more legal systems, a hypothesis which will be used as catalyser for further observations on the potential externalisation of legal norms from national legal orders to international level, in the case of bottom-up vertical methodology of comparison (i), respectively the potential internalisation of legal norms by national systems which imported an international or a foreign matrix of legal concepts, in the case of topdown vertical comparison (ii). During the second stage of vertically applied comparative methodology, the researcher elaborates 'a conceptual model is constructed that serves as the basis for comparison between national and international legal systems' ${ }^{10}$. MOMIROV and FOURIE also offer details on stage three of the vertical comparative methodology, stating that it involves 'a systematic (vertical) comparison between national and international legal systems'11, which on further stage provides a solid basis for drawing conclusions on the potential externalisation/internalisation of legal norms by the national legal orders under observation. More importantly, the cited authors explain that at the core of the vertical or cross-echelon legal comparative process stays an estimation made by the researcher on the 'similarities and differences'12 between the conceptual frame relevant for the international legal order which represented the object for comparison and the legal concepts which seemed to had been internalised or, upon the case, externalised from national legal orders. 


\subsection{Vertical and horizontal comparative methods in sepia tones}

While vertical comparative analysis allows researchers to determine the manner in which Consumer Law institutions and trends has been approached in several national legal systems, horizontal analysis can be additionally used to compare conceptual trends in relation to the appliance of international treaties by national organisms. Horizontal comparative analysis looks at the trend of Consumer protection tools over multiple periods, using a specific base period of reference. Thus, horizontal comparison typically shows the changes of perspective in Consumer Law national systems. In the field of bilateral Comparative Consumer Law, the comparison is carried out between two legal systems, which imply a thorough research of two judicial sources, while in multilateral comparative law, the comparison which takes place between more than two legal systems may be characterised as a variable-oriented research, the main advantage of which is the increasing number of the objectives compared. The comparative study of Consumer Law institutions and concepts in a positivist manner can also benefit form the use of longitudinal comparison, based on analogies which are made between legal systems of the past, in order to extract essential features valuable in the approaching of contemporary legal orders; in an antagonistic manner, the traverse comparative approach of Consumer Law valorises the main trends of contemporary legal orders, while simultaneously approaching features from several contemporary legal systems.

\subsection{The Achilles' heel of the vertical comparative approaches}

One should mention that the first argument against using bottom-up vertical comparison relates to the legitimacy of that enterprise ${ }^{13}$ as applicable to Consumer Law mechanisms. It should be underlined that the objection is based on classic sovereignty theory, as well as on a state-centred image of national law, which conceives Consumer Law, especially due to its preaeminent mandatory nature, as a body of rules enforceable through adjudication, with an emphasis on rule-orientation. Under multiple aspects, foreign law is not recognized prima faciae as a valid source of law by the national legal systems, 
unless it involves specific adhesion to international treaties or unless it derives from the transposing into national legal order, by the national legislator, of a body of specific rules. For that reason, it has been considered that the national legal system cannot cope with the migration of national injunctions, for instance, through a comparative approach to Consumer Law. In practice, this means that analysts are not permitted to rely on foreign law in order to fill gaps when national positive law is insufficient or incoherent. Arguably, if foreign law is not an authoritative legal source for national legal practitioners, then the legitimacy of the vertical bottom-up comparative method might be approached in a highly reticent manner, as referring to the transposition of legal concepts from national to international level14. Importing foreign legal ideas or legal concepts from international law into the national legal arena ${ }^{15}$ might have the meaning of "divorcing those legal ideas from the cultural context in which they originated', as MOMIROV and FOURIE wrote ${ }^{16}$.

In my opinion, the criticism which surrounded the bottom-up vertical comparison is far from been immutably correct. While the legal hypostasis of 'externalized' national mandatory rules embodies a traverse legal approach of this phenomenon and, hence, the 'externalization' cases of national legal norms are reined, by what is called a 'type of international influence', the public policy hypostasis depicts a more culturally-challenging type of relationship between administrative bodies and national subjects. Although we are discussing about the quasi-impossible, yet not so far-reaching, transposition of legal concepts from national to international level, researchers often find themselves trapped in a legal paradox: on one side, mandatory rules of public order are not and cannot be functioning, not even existing in the same way in all legal systems, mainly due to the fact that they have had a completely different evolution of the conceptual context in different national legal orders.

Using vertical bottom-up comparison for approaching the cases of absorption, in foreign law, of several legal concepts extracted from national legal orders, might also be surrounded by difficulties related to the lack of insight into the subjacent jurisprudence ${ }^{17}$. Let us note, from this perspective, that the comparison of two or more cases of externalized or internationallyabsorbed administrative legal concepts does not exhaust itself in the longitudinal 
comparison of their positive legal provisions, seen from the angle of their historical past-to present evolution, but needs to be praemised on the traverse comparative approaching as well, from the angle of political, historical, socio-cultural and, last but not least, philosophical foundations on which that particular legal regime rests. Not only can vertical comparative methodology sometimes require sufficient knowledge of another legal cultural background, but it always requires a sound understanding of past-to-present evolution and conceptual trends characterizing the compared legal orders ${ }^{18}$.

\section{Typologies of vertical and horizontal comparative approaches of Consumer Law}

In this first part we discuss certain cornerstones of vertical comparative methods, pertaining to the externalization of legal norms and regulations by national legal orders, through the means of vertical, 'bottom-up' legal comparison, as referring to the transposition of legal concepts from national to international level (section 3.1.). Before concluding the part focused on methodological typologies, we assess the relationship between top-down vertical methods of comparison, on one hand and bottom-up vertical comparative methods (section 3.2.).

\subsection{Is there a place for hybrid/cross-echelon methods of comparison?}

Notwithstanding the fact that vertical comparison of Consumer Law institutions involve primarily vertical conceptual approaches, since it involves the transposition of legal concepts from the national to the international level, in certain cases it might be useful to incorporate elements of horizontal legal comparison, as this section illustrates.

Regarding the problematic of cross-echelon methodology of comparison, three remarks deserve to be noted. Firstly, in cross-echelon multicultural comparisons, conducted between legal systems which do not belong to the same legal culture, attention should be paid to the fact that horizontal comparisons can 
also benefit form the use of longitudinal comparison, based on analogies which are made between legal systems of the past, in order to extract essential features valuable in the approaching of contemporary legal orders. Secondly, it appears preferable to avoid using a single-based echelon of comparison, while decrypting the common usage of conceptual frameworks in several national legal orders, unless the concepts subject to investigation present an intrinsic specificity. Thirdly, the terminological wavering is accentuated by the fact that the national legal texts and case law might show that conceptual recourse is necessary to be made to other complementary legal terms, greater or lesser in number depending on the conceptual framework which is examined.

To marshal but one other illustration, since numerous national legal systems use the term of 'indemnity', cross-echelon comparison might help clarifying the extent to which the mentioned concept included different types of damages or remunerations in several Consumer Law systems. Under Italian law, the mechanism of indemnity guaranties compensation in the event of a loss, the term 'indemnity' being sometimes used as a synonym of 'risarcimento' or compensation, while in French, Belgian and Swiss law, as SAUTONIE and TENENBAUM noticed ${ }^{19}$, references are made to 'indemnity for an eviction', 'non-competition-indemnity', 'redundancy payment' or 'compensatory payment', as opposed to German Law, under the dispositions of which the term 'indemnity' is often used as a general notion covering both the damages in the narrowest sense of the term, as well as other mechanisms of restitution. These terms do not refer to a uniform notion, being possible to imply inconsistent conditions of appliance, as well as different legal instruments of enforcement, in which the use of cross-echelon methodology of comparison might help avoiding conceptual misrepresentation.

\subsection{Top-down vertical methods of comparison vs Bottom-up vertical comparative methods}

As MOMIROv and Fourie (2009) underlined ${ }^{20}$, legal comparison applied to legal concepts is primarily 'horizontal', occurring among legal systems belonging to the same level or echelon and, on the other hand, 'vertical methodology' may also be applied, occurring among legal systems 
not belonging to the same level, i.e. cross-echelon approaching of Consumer Law institutions/concepts. Within this primary typology, the cited authors had foreseen four potential (secondary) modes of legal comparison: (a) horizontal, among legal systems at the national level (for instance, in the case of comparative constitutional law ${ }^{21}$ and conflict of law studies) and (b) horizontal comparison methods, among legal systems or regimes at the international level (for example, in hypotheses in which international institutions or compliance mechanisms of Consumer Law are compared, respectively in cases in which a treaty in one area of international law is compared to a proposed treaty in a different area of international legal order ${ }^{22}$ ).

Nevertheless, legal comparison might also be identified with (c) 'topdown' vertical methodologies applicable to Consumer Law institutions or mechanisms, typically used, for example, in approaching in a comparative manner the cases in which national law is required to incorporate international concepts into the national legal system, ideology and legal terminology, in the context of the internalisation of international norms and regulations by national legal orders, whereby national law is subject to an internalisation of regulations, while incorporating international concepts into the national legal system. The fourth mode of legal comparison which might be valorised in the study of contemporary Consumer Law concepts is the vertical 'bottom-up' approaching, which reflects the method discussed in this article, and the risks and benefits of which will be expounded in a detailed manner in the following sections.

Vertical, 'bottom-up' legal comparison, as defined by specialised literature ${ }^{23}$, extracts its fundamentals from the transposition of legal concepts or the conceptual structure behind them, from national to international level. As we reassess the vertical methodology of comparative law, we need also to mention that longitudinal/traverse comparative approaching may be associated with a multicultural/monocultural approaching of Consumer Law institutions, using, upon the case, a micro/macro level of comparison between national legal orders. It is important to underline that the micro/macro dimension of vertical comparative approaching is related to the extent to which different legal systems are compared as receptacles of internalised legal concepts; it is fundamentally a question of a micro/ macro scale of comparison, applied to cases of externalisation of national legal concepts at international scale or, 
upon the case, the internalisation of foreign legal concepts. On the micro level of comparison, it is possible to compare different institutions of Consumer Law, while at the macro level it is the function of conceptual frames in national legal systems and their fundamental characteristics that are subject to vertical top-down/bottom-up comparison. As BRAND observed ${ }^{24}$, when horizontal comparative law is of practical nature, it is also often traverse, mainly due to aspects related to the national legislator pursuing of a certain legal solution, while usually not being interested in the rules and regulations or legal history of the past, which in that particular case did not serve as cornerstones for the emerging of positivist legal concepts. On the other hand, longitudinal comparison takes its point of comparison from legal history and therefore it is often seen as being more theoretical of nature ${ }^{25}$, while aiming at general knowledge of Consumer Law institutions, taking into account that, in longitudinal comparative approaching of Consumer Law or comparative legal history of Consumer Law mechanisms, the researcher compares several legal systems seen in different periods of time.

The time variable or the depth dimension can be associated in a hybrid comparative scheme with the multicultural comparison, conducted between national legal systems which do not belong to the same legal culture $^{26}$. It is also necessary to draw attention to the fact that the analogies which are made between historical legal systems are used in longitudinal comparison as pillars for studies on recent developments which valorised traditional views on national legal concepts, while multilateral comparisons are carried out among a plurality of legal systems.

Thus it is useful to summarize that vertical comparisons involve legal systems belonging to different spheres along the spectrum - national, regional and international, while horizontal comparisons involve legal systems belonging to the same level. Multicultural comparisons are conducted between legal systems which do not belong to the same legal culture. At the same time, attention should be paid to the fact that horizontal monocultural comparisons, taking take place between two or more legal systems belonging to the same legal culture, may be subject to comparison of certain specific issues, making use of the micro-level traverse comparative method. 


\section{Which practical aspects are persistent in upward, downward and horizontal comparison?}

A common problem with horizontal comparative analysis is that the aggregation of information on the national transposition of Consumer Law concepts needs to be addressed for specific periods of time. In law enforcements, for instance, the peculiarity of this matter is reflected particularly in the comparative approaching of the emerging of professionals precontractual liability in cases in which a lawful claim withdrawal exists; it is the case, for example, of rectius repeal of adjudication in the case of manufacturers' liability for defective products or in the hypotheses of unsuccessful drawing up of the contract where the professional party fails to inform the consumer on all essential aspects. When conducting a horizontal comparative analysis on national approaching of professionals' liability, it can be underlined that usually pre-contractual liability can be found in the case of a reasonable entrusting infringement by private subjects, associated with the breach of the duty of information related to all the events in a proceeding and responding to the interests of private subjects. In this context, vertical comparative approaches permit to observe that the obligations connected to administrative action effectiveness are essentially correlated and commonly shared by the duty of diligent behaviour according to good faith and to the equity principle. Vertical top-down analysis is also useful to examine the obligations of information in terms of consumer protection mandatory rules, which aim at neutralizing the cognitive asymmetries and the drawing up of contracts made in informative equality conditions; halfmandatory rules on the duty of information, in such context, serves as an assumption for private subjects who are interested in creating an efficient pre-contractual relationship between consumers and professionals.

Vertical comparative approaches are also helpful in investigating the national 'absorption' of specific regulations on the Public administrations pre-contractual liability, which takes shape in all the cases where public institutions entering into transactions or relationships with third parties, acting or omitting to act, opposite to correctness and good faith. As PASCARIU argues $^{27}$, Public administration is obliged to respect correctness and the rules associated with good faith, as primary duties guaranteed by legal system. 
As comparative vertical analyses have shown, Public administration's behaviour evaluation is aimed to assess if it has acted in favour of public interest, but also if it has operated as a correct contracting party since all the phases of a public evidence procedure serve as a tool for the progressive formation of the consent ${ }^{28}$.

For example, longitudinal comparative approaching of professionals' extra-contractual liability has shown that, in several legal systems, the mentioned concept has been seen as a kind of contractual liability deriving from the 'pre-contractual phase' between consumers and professionals ${ }^{29}$. Therefore, the similarities with the contractual approach allowed the researchers to observe national references to the rules related to a contractually-formed relationship, those connected to liability in particular being applied. As PASCARIU has shown, 'The branch of the law covering culpa in contraendo, does not need, indeed, a personalized relationship between public administration and private subjects because it would find its only source in the adjudication measure, but it has to protect the legitimate entrusting in the correctness' 30 of the pre-contractual relationship. As concerning the public evidence phase, it has been noted that pre-contractual liability can also be found whether before or after the adjudication of a contract between professionals and consumers, based on the concept of legitimate entrustment shaping the relationship between the contractual parties ${ }^{31}$. As a consequence, if these principles are not respected, pre-contractual liability begins to exists while pre-contractual liability stands as condicio iuris ${ }^{32}$, as a guaranty of the contract effectiveness together with the reciprocal obedience towards the rules of good faith.

As an explanatory example of vertical comparative approaches of Consumer Law, one can use the comparative analyses at national level on the judicial meaning of the notion of mandatory rules and the various degrees in the extent to which a mandatory rule must be applied through the means of an administrative act, in the field of public policy oriented towards consumer protection. A twofold distinction is made between (a) mandatory rules of public policy, on one hand and (b) mandatory rules concerning private interests, on the other. The main objective of the comparative vertical analyses was to deliver a set of characteristics for the applications of corrective mandatory rules and to observe, trough the means of a brief inventory of the legal 
remedies accepted in different national legal systems, the role played by mandatory rules in erasing disequilibria existing between consumers and other participants, in response to the presumably intrinsic vulnerability of the latter.

The vertical micro-based comparison was meant to primarily dwell upon a third set of limitations concerning the territorial scope of mandatory rules $^{33}$ of consumer protection; for instance, The Common European Sales Law may only be used for cross-border contracts, while Member States may however allow its use also for domestic transactions. This restriction to consumer contracts recalls the intense efforts which were made at European level over the course of several decades to define the scope of the administrative mandatory rules. Also to be discussed through the means of comparative approaching, was the meaning of mandatory rules of public policy as compared with domestic contracts under conditions of mandatory rules concerning public interests. A further point of concern related to transactions involving professionals and profane consumers. As opposed to the comparative utilitarian approaches of Consumer Law, it should also be taken into account that the notion of public policy has the purpose of safeguarding society's fundamental values, although its content and margins tend to vary between different branches of law. Recent trends in Consumer Law changed the perspective, enhancing disequilibria existing between parties; it follows from the principle of freedom of contract that whenever a rule is not mandatory, the parties are allowed to deviate from it. However, there are certain limitations to be observed in the perimeter of the mentioned category of rules. For example, deviation is allowed only in the interest of one party (the one who is protected by the non-mandatory rule), as national legal systems include many examples. In other cases, deviation is permitted, but only marginally, as the parties can modify the rule or exclude some of its specific consequences, but they are not allowed to touch upon its 'core' or to exclude it 'as such'. The best example is probably the domain of public policy of mandatory nature involving situations of asymmetrical distribution of information between the parties, to the extent that such informational asymmetries create an unbalanced contractual content.

The comparative study of contemporary Consumer Law institutions and legal mechanisms can also benefit form the use of longitudinal comparison, 
based on analogies which are made between legal systems of the past, in order to extract essential features valuable in the approaching of contemporary legal orders; in an antagonistic manner, the traverse comparative approach of Consumer Law valorises the main trends of contemporary legal orders, while simultaneously approaching features from several contemporary legal systems. For that reason, traverse comparison might help depicting the manner in which the national legal systems cope with the migration of constitutional or administrative ideas, in order to fill gaps when national positive law is insufficient per se. Vertical comparative observations may also be made on the potential externalisation of legal norms from national legal orders to international level, in the case of bottom-up vertical methodology of comparison, respectively the potential internalisation of legal norms by national systems which imported an international or a foreign matrix of legal concepts, in the case of top-down vertical comparison.

Hybrid vertical comparative methods are illustrated by vertical multilateral comparisons, which are carried out among a plurality of legal systems, involving legal systems belonging to different spheres along the national, regional and international spectrum; multicultural comparisons, which are conducted between legal systems which do not belong to the same legal culture may be seen as an alternative to monocultural comparisons launched between two or more Consumer Law systems belonging to the same legal culture. While vertical, top-down methods of comparison are most likely to be practiced in the field of Consumer Law research, typically in the context of the internalisation of international norms and regulations by national legal orders, vertical, 'bottom-up' legal comparison refers to the transposition of legal concepts from national to international level. Attention should be paid to the fact that, in cross-echelon multicultural comparisons, conducted between legal systems which do not belong to the same legal culture comparative conclusions tend to be based on analogies which are made between legal systems of the past (in order to extract essential features valuable in the approaching of contemporary legal orders at the macro level) it is the function of conceptual frames in national legal systems and their fundamental characteristics that are subject to vertical top-down/bottom-up comparison. The potential internalisation of legal norms by national systems importing an international or a foreign conceptual framework might be 
illustrated in the manner of a top-down vertical comparison. Typically, national legal orders were likely to be seen as receptacles for international legal norms and therefore to incorporate international concepts into the national legal system, terminology and ideology, vertical 'bottom-up' legal comparison, on the other hand, had raised the question of the pertinence of legal transposition in terms of concepts or ideas behind those concepts, from national legal order to international legal order.

\section{Conclusive remarks}

Far from having a shadowy nature, vertical comparative methods applied to the study of contemporary Consumer Law permit the mapping of the internalisation or, upon the case, the externalisation of Consumer Law concepts from national to international level. The core of this issue was focused on the concept of vertical bottom-up comparison, as well as on the longitudinal versus traverse comparative analyses of Consumer Law concepts and trends. As an illustration, we used the example of comparisons between national approaches on contractual discretionary powers, which permitted to evaluate whether professionals acted in a correct, equitable way or not; as a consequence, consumers may be authorized to advocate the principle of reliance comparing the risk of a good outcome of the transaction with the professionals. The vertical bottom-up mode of legal comparison has conventionally been viewed with scepticism due to the assumption of inherent incompatibility between the national and international legal orders, as receptacles of administrative norms. The criticism to this statement was focused on the principle of transposing legal concepts from national to international level, which is possible by virtue of the permeable nature of mandatory legal concepts. Fundamentally, such a kind of exclusion was due to the postulate stating that during the drawing up of an international set of legal norms, previous national approaches tend to be ignored unless they present certain elements of uniformity. Nevertheless, national public administration, acting as iure privatorum, is able to determine the final phase in the adoption of legal concepts and mechanisms. From this perspective, the comparison of multiple public administration systems is far from exhausting itself in the 
comparison of their positive legal provisions, but needs to be praemised on de lege ferenda trends of historical, socio-cultural, political and philosophical foundations from which the Consumer Law of the particular legal regime extracted its conceptual roots.

The following conclusions may be extracted from the above considerations on the use of vertical versus horizontal comparative methods in the field of contemporary Consumer Law:

(a) vertical, top-down methods of comparison are most likely to be practiced in the field of Consumer Law research, typically in the context of the internalisation of international norms and regulations by national legal orders; on the opposite, vertical, 'bottom-up' legal comparison, contextualising the transposition of legal concepts from national to international level, has conventionally been viewed with scepticism as applicable to the study of Consumer Law institutions, due to the assumption of inherent incompatibility between the national and international legal orders in terms of legal transplants;

(b) whereby national legal orders are likely to be seen as receptacles for international legal requirements and therefore to incorporate international concepts into the national legal system, terminology and ideology, vertical 'bottom-up' legal comparison, on the other hand, had raised the question of the pertinence of legal transposition in terms of concepts or ideas behind those concepts, from national legal order to international legal order;

(c) in the field of bilateral comparative Consumer Law, the comparison is carried out between two legal systems, which imply a thorough research of two judicial sources, while in multilateral comparative law, the comparison which takes place between more than two legal systems may be characterised as a variable-oriented research, the main advantage of which is the increasing number of the objectives compared;

(d) the comparative study of contemporary Consumer Law institutions and legal mechanisms can also benefit form the use of longitudinal comparison, based on analogies which are made between legal systems of the past, in order to extract essential features valuable in the approaching of contemporary legal orders; in an antagonistic manner, the traverse comparative approach of Consumer Law valorises the main trends of contemporary legal orders, while simultaneously approaching features from several contemporary legal systems; 
(e) hybrid vertical comparative methods are illustrated by vertical multilateral comparisons, which are carried out among a plurality of legal systems, involving legal systems belonging to different spheres along the spectrum - national, regional and international; multicultural comparisons, which are conducted between legal systems which do not belong to the same legal culture may be seen as an alternative to monocultural comparisons launched between two or more Consumer Law systems belonging to the same legal culture;

(f) as an explanatory example of vertical comparative approaches of Consumer Law, one can use the comparative analyses at national level on the judicial meaning of the notion of mandatory rules and the various degrees in the extent to which a mandatory rule must be applied through the means of an administrative act; in national legal orders, the mandatory started first from a background involving a tort liability, based on culpable behavioural elements, which has progressively developed towards the direction of extra-contractual culpable gestures and finally settled on the contractual framework of the relationship between Public administration and its subjects;

(g) vertical comparative approaches are also helpful in investigating the national 'absorption' of specific regulations on the professionals' pre-contractual liability, which takes shape in all the cases where professionals entering into transactions or relationships with profane consumers; as comparative vertical analyses have shown, professional's behaviour evaluation is aimed to assess if it has acted in favour of public interest of consumers, but also if it has operated as a correct contracting party since all the phases of a public evidence procedure serve as a tool for the progressive formation of the consent.

\section{* Lecturer, PhD. Faculty of Law Babes-Bolyai University of Cluj-Napoca; e-mail: juanitag@law.ubbcluj.ro}

${ }^{1}$ For important comments, see A. Momirov, A. Naudé Fourie, 'Vertical Comparative Law Methods: Tools for Conceptualising the International Rule of Law', Erasmus Law Review Vol. 2, Issue 3 (2009), p. 291-309; E. J. Eberle, 'The Method and Role of Comparative Law', Washington University Global Studies Law Review Vol. 8, Issue 3 (2009), p. 451485; R. Hirschl, 'The Question of Case Selection in Comparative Constitutional Law', The American Journal of Comparative Law Vol. 53, No.1 (2005), p. 125-156; G. Samuel, 'Taking Methods Seriously (Part Two)', Journal of Comparative Law No. 2 (2007), p. 210-218; V. V. Palmer, 'From Lerotholi to Lando: Some Examples of Comparative Law Methodology', American Journal of Comparative Law Vol. 53 (2005), p. 261-268; D. Kennedy, 'The Methods 
and the Politics', Comparative Legal Studies: Traditions and Transitions', Eds. Pierre Legrand and Roderick Munday, Cambridge: Cambridge University Press (2003), p. 352-357; Ë. Örücü, 'Methodological Aspects of Comparative Law', European Journal of Law Reform Vol. 8 (2006), p. 29-36; O. Brand, 'Conceptual Comparisons: Towards a Coherent Methodology of Comparative Legal Studies', Brooklyn Journal of International Law No. 32 (2007), p. 405-412; R. Hirschl, 'From comparative constitutional law to comparative constitutional studies', International Journal of Constitutional Law Vol. 11, No. 1 (2013), p. 6-12; P. Ridola, 'Diritto comparato e diritto costituzionale europeo', Editore Giappichelli (2010), Roma, p. 245-251.

${ }^{2}$ See, for further details, D. Pieters, 'Functions of Comparative Law and Practical Methodology of Comparing', Syllabus Research Master in Law, Leuven University, 2009, p. 12-35.

3 For further details, see R. Hirschl, 'The Question of Case Selection in Comparative Constitutional Law', in The American Journal of Comparative Law Vol. 53, No.1, 2005, p. 125-156.

4 E. J. Eberle, 'The Method and Role of Comparative Law', in Washington University Global Studies Law Review Vol. 8, Issue 3, 2009, p. 457.

5 See J. E. K. Murkens, 'Comparative Constitutional Law in the Courts: Reflections on the Originalists' Objections', London School of Economics and Political Science Working Papers 15/2008, p. 38.

${ }^{6}$ For several arguments, see A. Momirov, A. Naudé Fourie, 'Vertical Comparative Law Methods: Tools for Conceptualising the International Rule of Law', cit. supra, p. 298.

7 See, for further details, F. Bignami, 'Comparative Administrative Law', Public Law and Legal Theory Paper No. 115, 2012, p. 11.

${ }^{8}$ See P. G. Monateri, 'Methods of Comparative Law', University of Turin, Research Handbooks in Comparative Law, 2012, p. 27.

9 See A. Momirov, A. Naudé Fourie, 'Vertical Comparative Law Methods: Tools for Conceptualising the International Rule of Law', cit. supra, p. 298-301.

10 Ibidem.

${ }^{11}$ Idem, p. 299.

12 Ibidem.

13 See A. Watson, 'Legal Transplants: An Approach to Comparative Law', Athens and London: The University of Georgia Press, 1974, p. 12.

14 See, for further readings, P. Kahn, 'Comparative Constitutionalism in a New Key', in Michigan Law Review Vol. 101, 2003, p. 2677-2685.

15 See B. Grossfeld, E. J. Eberle, 'Patterns of Order in Comparative Law: Discovering and Decoding Invisible Powers', in Texas Law Journal Vol. 38, 2003, p. 292; M. Reimann, 'The Progress and Failure of Comparative Law in the Second Half of the Twentieth Century', in American Journal of Comparative Law, Vol. 50, 2002, p. 671-673.

${ }^{16}$ See A. Momirov, A. Naudé Fourie, 'Vertical Comparative Law Methods: Tools for Conceptualising the International Rule of Law', cit. supra, p. 299. See also K. Tuori, 'Legislation Between Politics and Law', in L. J. Wintgens (ed.), 'Legisprudence: A New Theoretical Approach to Legislation', Oxford: Hart Publishing, 2002, p. 105-107.

17 See G. Frankenberg, 'Critical Comparisons: Rethinking Comparative Law', in Harvard International Law Journal 1985, Vol. p. 411-419; V. Terzea, 'Protecția consumatorilor. Jurisprudența Curții de Justiție a Uniunii Europene', București: Universul Juridic, 2017, p. 51-58. 
18 V. Curran, 'Dealing in Difference: Comparative Law's Potential for Broadening Legal Perspectives', in American Journal of Comparative Law 1998, Vol. 46, p. 657-661.

${ }^{19}$ See J. B. Racine, L. Sautonie, A. Tenenbaum, G. Wicker, 'Damages and Indemnity - Comparative Law (Chapter 8)', in B. Fauvarque-Cosson, D. Mazeaud (eds.), 'European Contract Law. Materials for a Common Frame of Reference: Terminology, Guiding Principles, Model rules', Munich: Sellier, 2008, p. 317.

${ }^{20}$ See, for further details, A. Momirov, A. N. Fourie, 'Vertical Comparative Law Methods: Tools for Conceptualising the International Rule of Law', cit. supra, p. 294-295.

${ }^{21}$ For further details, see L. Epstein, J. Knight, 'Constitutional Borrowing and Nonborrowing', in International Journal of Constitutional Law Vol. 1, No. 2, 2003, p. 196-198.

${ }^{22}$ See P. Legrand, 'Public Law, Europeanisation, and Convergence: Can Comparativists Contribute?', in P. Beaumont, C. Lyons, \& N. Walker (eds.), 'Convergence and Divergence in European Public Law', Oxford: Hart Publishing, 2002, p. 89; W. Menski, 'Comparative Law in a Global Context: The Legal Systems of Asia and Africa', Cambridge: Cambridge University Press, 2nd ed., 2006, p. 30-34; S. Choudhry (ed.), 'The Migration of Constitutional Ideas',Cambridge: Cambridge University Press, 2006, p. 81-93.

23 For further details, see O. Brand, 'Conceptual Comparisons: Towards a Coherent Methodology of Comparative Legal Studies', Brooklyn Journal of International Law No. 32 (2007), p. 405407; Ch. Knill, J., 'Post-Accession Transposition of EU Law in the New Member States: A Cross-Country Comparison', European Integration online Papers (EIoP), Vol. 13, No. 2, 2009, p. 18-26; R. Scarciglia, 'Comparative Law and Administrative Citizenship in the Balkan Area', Intercultural Dialogue and Citizenship, University of Trieste Research Papers 2007, p. 621-640; C. Vrabie, M. K. Öktem, 'Comparative Study on Local E-Government. Romania and Turkey' EIRP Proceedings 2013, p. 19-26; S. Antoniazzi, 'La tutela del legittimo affidamento del privato nei confronti della pubblica amministrazione', Torino: Giappichelli, 2005, p. 91; D. Baranger, C. Murray, 'Systems of government', in M. Tushnet, T. Fleiner and C. Saunders (Eds.), 'Routledge Handbook of Constitutional Law'. Oxon: Routledge, 2013, p. 112.

24 See O. Brand, 'Conceptual Comparisons: Towards a Coherent Methodology of Comparative Legal Studies', cit. supra, p. 408.

25 Ibidem.

26 Idem, p. 409.

${ }^{27}$ See L. Pascariu, 'Some Ideas for a Comparative Analysis of the Administrative Contracts', European Journal of Law and Public Administration, 2016, Volume 3, Issue 1, p. 117.

${ }^{28}$ See J. Goicovici, 'Fornarea progresivă a contractului (Progressive Formation of Contracts)', Bucharest: Wolters Kluwer, 2009, p. 39.

${ }^{29}$ See, for a synopsis of possible explanations, L. Pascariu, 'Some Ideas for a Comparative Analysis of the Administrative Contracts', cit. supra, p. 116.

30 Ibidem.

${ }^{31}$ Idem, p. 118.

${ }^{32}$ Idem, p. 119.

33 See J. Goicovici, 'Mandatory Rules of Public Policy concerning consumer protection in recent jurisprudence', in Transylvanian Review of Administrative Sciences No. 38, 2013, p. 76-78. 